\section{Drip Irrigation Affects the Morphology and Distribution of Olive Roots}

\author{
Shixin Deng, Qun Yin, Shanshan Zhang, Kankan Shi, Zhongkui Jia ${ }^{1}$, \\ and Luyi Ma ${ }^{1}$ \\ Forestry College, Beijing Forestry University, No. 35 Qinghua East Street, \\ Beijing 100083, China; Ministry of Education Key Laboratory of Silviculture \\ and Conservation, Beijing Forestry University, Beijing 100083, China
}

Additional index words. Olea europea, surface drip irrigation, irrigation amount, root length density, root surface area

\begin{abstract}
Under field conditions, this study investigated the influence of the irrigation amount on olive root morphology and spatial distribution. Soil samples were taken with an auger at distances of 30,60 , and $90 \mathrm{~cm}$ from the tree trunks in four directions. The roots were analyzed using an Epson Twain Pro root scanning system. The results indicated that under different irrigation treatments, the indicators of root morphology of different varieties showed different responses to the irrigation amount. The root length density (RLD), root surface area (RSA), and root volume (RV) of Arbosana first increased with increasing irrigation amount but then decreased; however, those of Arbequina monotonically increased with increasing irrigation amount. The root average diameter of the two varieties was inversely proportional to the irrigation amount. In the vertical dimension, the RLD and RSA of each treatment decreased with increasing soil depth and were mainly distributed in the surface soil (0-20 cm in depth). The RLD and RSA in the vertical direction (VD) of the drip irrigation belt were higher than those of the belt in the parallel direction (PD), and the range was $12 \%$ to $86 \%$. Compared with the roots of the 0 - to $20-\mathrm{cm}$ soil layer, the roots of the $20-$ to $40-\mathrm{cm}$ and $40-$ to $60-\mathrm{cm}$ soil layers were more influenced by the irrigation amount. Horizontally, the RLD and RSA decreased with increasing radial distance. The $30-\mathrm{cm}$ radial area contained most roots, the proportion of roots in this region increased with increasing irrigation capacity. The influence of irrigation quantity in the PD of the drip irrigation belt was greater than that in the VD. The results suggest that irrigation does not change the root spatial distribution pattern but does promote root growth. The two varieties had different responses to irrigation. In terms of soil moisture levels after irrigation, $75 \%$ of field capacity is appropriate for 'Arbosana', whereas $\mathbf{1 0 0 \%}$ is advisable for 'Arbequina'. To improve water use efficiency, moisture should be irrigated within the $30-\mathrm{cm}$ radial distance from the trunk, and irrigation depth is not easy to more than $20 \mathrm{~cm}$. This study provides a scientific basis for the efficient water management of olive trees.
\end{abstract}

Olive (Olea europea L.) trees are aiphyllium and subordinate members of Olea of the Oleaceae family. Originating in the Mediterranean, the olive tree is regarded throughout the world as an important type of oleiferous tree. Because olive oil contains various natural nutrients, such as unsaturated fatty acids, phenols, and vitamins, among others, it has been considered "liquid gold" (Vossen, 2007). During recent decades, olive has been widely introduced to America, Australia, Argentina, and other countries for its great economic value and edibleness. In the 1960s, the olive was first brought to China from Albania and was successfully grown (Breton et al., 2006). Since then, however, China has paid much more attention to introduction experiments, confirming and dividing

Received for publication 6 Apr. 2017. Accepted for publication 25 July 2017.

This research was financially supported by the Special Fund for Forest Scientific Research in the Public Welfare under Grant No. 201204410.

${ }^{1}$ Corresponding authors. E-mail: jiazk@bjfu.edu. cn or maluyi@bjfu.edu.cn. a tendency to maintain a constant root-toleaf water gradient. However, irrigation alters the water and nutrient status of the soil. Roots are the primary organ of plants that absorbs water and nutrients in the soil, and roots act as the dynamic interface between the plants and soil (Gordon and Jackson, 2000). The root morphology and distribution in the soil directly affect the growth of the aboveground parts and the efficiency of the absorption of water and nutrients (Ma et al., 2012). Root function is closely related to their morphology (Tang et al., 2010), and soil moisture directly and indirectly influences the growth and distribution of roots (Feng, 1996). The degree of availability of plants to absorb water and nutrients depends on the root morphology and competitive ability (Schenk and Jackson, 2002). Quantitative studies of root morphology and distribution characteristics have played a vital role in establishing models of root absorption and transportation of water, improving water management in woodlands and the development of water-saving forestry (Xi et al., 2011).

In recent years, many studies concerning the effect of irrigation on roots have been reported both domestically and abroad. Levin et al. (1979) studied the soil moisture and root system distribution covered a wider area when irrigated twice a week with $81 / \mathrm{h}$ tricklers rather than by irrigating every day or once a week with $41 / \mathrm{h}$ tricklers. Zhao et al. (2012) reported that surface drip irrigation caused the roots of Elaeagnus angustifolia to be distributed in the topsoil and that the root biomass and the number of thick roots increased with the irrigation amount. Zhang et al. (2013) reported that subsurface drip irrigation did not change the vertical distribution pattern of the fine roots of Populus tomentosa; however, it did enlarge the biomass and volume of those roots, and the irrigation caused the RLD and organization density of each soil layer to be consistent. Nevertheless, studies on how irrigation affects the morphology and distribution of the olive root system have less been conducted. Therefore, a study about how irrigation affects the root morphology and distribution will help not only to determine the spatial distribution characteristics of olive roots and provide information about how different varieties respond to irrigation but will also guide efficient water management, which, consequently, involves optimal water control and efficient use in olives.

The objectives of this study were to 1) clarify whether irrigation influences the spatial distribution pattern of olive roots and 2) uncover the morphology and distribution characteristics of olive roots of different varieties relative to irrigation. The above information can provide a theoretical foundation to formulate a scientifically rational and efficient water management regime for olives. 
Table 1. Physical and chemical properties of soil at the experimental site.

\begin{tabular}{|c|c|c|c|c|c|c|c|c|c|}
\hline Depth $(\mathrm{cm})$ & $\begin{array}{c}\text { Bulk } \\
\text { density } \\
\left(\mathrm{g} \cdot \mathrm{cm}^{-3}\right)\end{array}$ & $\begin{array}{c}\text { Saturated water } \\
\text { content }(\%)\end{array}$ & $\begin{array}{l}\text { Total N } \\
\left(\mathrm{g} \cdot \mathrm{kg}^{-1}\right)\end{array}$ & $\begin{array}{c}\text { Available } \\
\mathrm{P}\left(\mathrm{mg} \cdot \mathrm{kg}^{-1}\right)\end{array}$ & $\begin{array}{c}\text { Available } \\
\mathrm{K}\left(\mathrm{mg} \cdot \mathrm{kg}^{-1}\right)\end{array}$ & $\begin{array}{c}\text { Sand } \\
(\%)\end{array}$ & $\begin{array}{l}\text { Silt } \\
(\%)\end{array}$ & $\begin{array}{l}\text { Clay } \\
(\%)\end{array}$ & $\begin{array}{c}\text { Soil } \\
\text { texture }\end{array}$ \\
\hline $0-20$ & 1.37 & 33.8 & 0.61 & 4.99 & 188.31 & 70.66 & 28.80 & 0.54 & Sandy loam \\
\hline $20-40$ & 1.33 & 35.1 & 0.52 & 4.82 & 193.22 & 66.07 & 33.36 & 0.57 & Sandy loam \\
\hline $40-60$ & 1.31 & 37.4 & 0.47 & 5.02 & 195.14 & 62.51 & 36.89 & 0.60 & Sandy loam \\
\hline
\end{tabular}

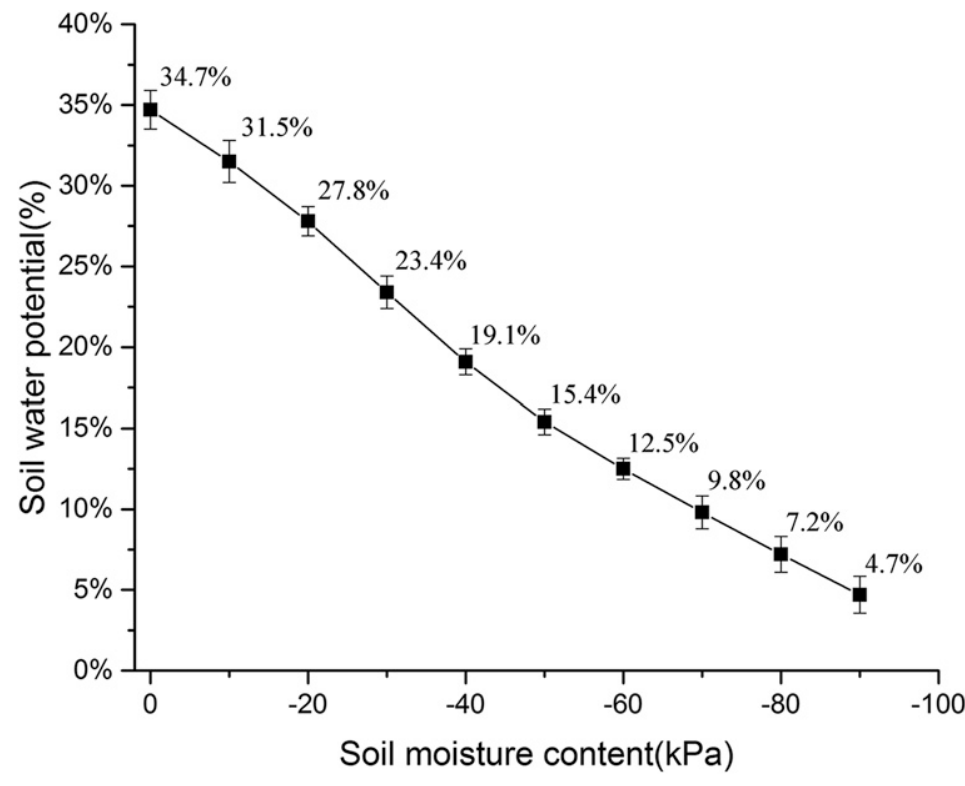

Fig. 1. Relationship between soil water potential and soil moisture content.

\section{Materials and Methods}

Study site. The study site was located at the Dabao olive base $\left(33^{\circ} 4^{\prime} \mathrm{N}, 104^{\circ} 92^{\prime} \mathrm{E}\right.$; $900 \mathrm{~m}$ elevation) in Wudu district, Longnan city, Gansu province. The district is of the northern subtropical semihumid climate, with an average annual rainfall of $474 \mathrm{~mm}$ that is generally concentrated in June through September. The average annual temperature is $14.9{ }^{\circ} \mathrm{C}$ (maximum $40{ }^{\circ} \mathrm{C}$, minimum $-11{ }^{\circ} \mathrm{C}$ ). The annual sunshine duration is $1912 \mathrm{~h}$, with a frost-free period of more than $270 \mathrm{~d}$. The soil texture is sandy loam; its physicochemical properties are shown in Table 1 and Fig. 1.

Experimental design. Two olive varieties were sampled, 'Arbosana' and 'Arbequina', both of which were introduced from Spain as 1-year-old cuttings in 2011. The average diameter of 'Arbosana' trees was $4.3 \mathrm{~cm}$, and the average height was $1.93 \mathrm{~m}$, whereas 'Arbequina' trees were $5.2 \mathrm{~cm}$ thick and $2.36 \mathrm{~m}$ tall. The trees were evenly planted at a density of $3.0 \times 3.0 \mathrm{~m}$. Two waterdripping lines were placed on the south and north sides along the trees, $30 \mathrm{~cm}$ away from trees. The drip lines ran east west, with a pipe diameter of $14 \mathrm{~mm}$ and emitter spacing of $30 \mathrm{~cm}$. The drip rate was $2 \mathrm{~L} \cdot \mathrm{h}^{-1}$.

The experiment adopted a randomized block design with four irrigation levels: T1 (soil moisture content maintained at $35 \%$ of field capacity after irrigation), T2 (55\%), T3 $(75 \%)$, and T4 $(100 \%)$. There were four treatments and three replications in total, and all blocks were random. A tensiometer was installed just below the emitter of T4. When the soil water potential was less than $-30 \mathrm{kPa}$, the olives in each level were irrigated. The irrigation volume was determined by the irrigation time, which was calculated by two equations: $t=[G \times$ $\left.\left(\mathrm{SWC}_{2}-\mathrm{SWC}_{1}\right)\right] /(V \times n)$ and $G=3.14 \times R^{2} \times$ $H \times k$ (Yan et al., 2015). ( $\mathrm{SWC}_{2}$ represents the proportion of soil moisture that accounts for field capacity, whereas $\mathrm{SWC}_{1}$ refers to the soil moisture before irrigation, measured by the oven-drying method. $V$ represents the rate of emitter flow per hour, which was $2 \mathrm{~L} \cdot \mathrm{h}^{-1} \cdot n$ is the number of emitters within the designated moisture radius. $G$ represents the weight of the designated moisture volume. $R$ represents the designated moisture radius, which was $100 \mathrm{~cm}$. $H$ represents the depth of the designated moisture, which was $60 \mathrm{~cm}$. $k$ represents the soil bulk density, which was $1.37 \mathrm{~g} \cdot \mathrm{cm}^{-3}$ ). The experiment implementation overview in trial sites are shown in Table 2.

Sampling design. Soil samples were taken with an auger $(8 \mathrm{~cm}$ of inner material and $20 \mathrm{~cm}$ of length) at the end of Oct. 2014 (the end of growing season). In the horizontal direction, the samples were taken at distances of 30,60 , and $90 \mathrm{~cm}$ from the tree trunks in four directions (east, south, west, and north of the trees). In the VD, the total soil volume was extracted at three soil depths $(20,40$, and $60 \mathrm{~cm}$ ) for each horizontal sampling distance (Fig. 2). Those samples from two directions (east and west) paralleling the drip line were marked as the PD, whereas the samples from the other two directions (south and north) perpendicular to the drip line were marked as the VD. The samples were dipped in water and then sieved by a $0.8-\mathrm{mm}$ mesh sifter to separate the roots from most of the soil, organic matter, and other impurities. All living roots were handled with tweezers and net spoons in water.

Photographs were taken using an Epson Twain Pro roots scanning system for each root sample, and the images were analyzed using the WinRhizo root image analyzer software to obtain the length, surface area, volume and mean diameter of the root segments individually for each sample.

Data analysis. The Shapiro-Wilk and Levene tests showed that the data conformed to the normal distribution and had equal variance. Excel 2013 and SPSS 20.0 statistical software programs were used for the statistical analysis. A one-way analysis of variance and the Duncan test were performed to analyze the variance and for multiple comparisons $(\alpha=0.05)$. Plots were constructed with Origin 9.2 and Surfer 8.0 software programs.

\section{Results}

Root growth response to irrigation. The RLD, RSA, RV, and root mean diameter (RMD) are important indexes for measuring root morphology characteristics. The changes of these root morphology characteristics are shown in Fig. 3, and the root growth indexes of olive trees showed obvious regularity with irrigation levels. However, the regulation was different between the two varieties. In 'Arbosana', the RLD, RSA, and RV increased when the irrigation was between $35 \%$ and $75 \%$ of field capacity but decreased when the irrigation was between $75 \%$ and $100 \%(\mathrm{~T} 3>\mathrm{T} 2>\mathrm{T} 4>\mathrm{T} 1)$. Each variable value of T2, T3, and T4 was markedly higher than those of T1 $(P<0.05)$. However, the differences between T2 and T3 and between $\mathrm{T} 2$ and $\mathrm{T} 4$ were not significant. For example, the RLD in T1 was 0.1129 $\mathrm{cm} \cdot \mathrm{cm}^{-3}$, whereas in T2, T3, and T4, the RLD values were $0.353,0.390$, and $0.280 \mathrm{~cm} \cdot \mathrm{cm}^{-3}$, respectively, which were $3.1,3.4$, and 2.5 times greater than that in T1, respectively.

The RLD, RSA, and RV all increased with increasing irrigation amount, reaching a maximum value when the soil water content was maintained at $100 \%$ of the field capacity (T4) in 'Arbequina'. Each variable value of T2, T3, and T4 was markedly higher than those of T1 $(P<0.05)$, but the value of RLD with no significant difference observed 
Table 2. The experiment implementation overview in trial sites.

\begin{tabular}{|c|c|c|c|c|}
\hline Treatment time (mo./d) & Treatment & $\mathrm{SWC}_{2}(\%)$ & $\mathrm{SWC}_{1}(\%)$ & Irrigation volume $(\mathrm{kg})$ \\
\hline \multirow[t]{4}{*}{3.16} & T1 & 12.1 & 23.4 & 0 \\
\hline & $\mathrm{T} 2$ & 19.1 & 23.4 & 0 \\
\hline & T3 & 26.0 & 23.4 & 67.1 \\
\hline & T4 & 34.7 & 23.4 & 291.7 \\
\hline \multirow{4}{*}{3.25} & $\mathrm{~T} 1$ & 12.1 & 9.7 & 61.9 \\
\hline & T2 & 19.1 & 9.8 & 240.0 \\
\hline & T3 & 26.0 & 13.9 & 312.3 \\
\hline & T4 & 34.7 & 23.4 & 291.7 \\
\hline \multirow[t]{4}{*}{4.5} & $\mathrm{~T} 1$ & 12.1 & 6.3 & 149.7 \\
\hline & $\mathrm{T} 2$ & 19.1 & 8.9 & 263.3 \\
\hline & T3 & 26.0 & 14.1 & 307.1 \\
\hline & T4 & 34.7 & 23.4 & 291.7 \\
\hline \multirow[t]{4}{*}{4.14} & $\mathrm{~T} 1$ & 12.1 & 6.1 & 154.9 \\
\hline & $\mathrm{T} 2$ & 19.1 & 8.8 & 265.9 \\
\hline & T3 & 26.0 & 14.2 & 304.6 \\
\hline & T4 & 34.7 & 23.4 & 291.7 \\
\hline \multirow[t]{4}{*}{4.27} & T1 & 12.1 & 6.5 & 144.5 \\
\hline & T2 & 19.1 & 9.2 & 255.5 \\
\hline & T3 & 26.0 & 14.6 & 294.2 \\
\hline & T4 & 34.7 & 23.4 & 291.7 \\
\hline \multirow{4}{*}{5.5} & T1 & 12.1 & 5.7 & 165.2 \\
\hline & T2 & 19.1 & 8.4 & 276.2 \\
\hline & T3 & 26.0 & 13.1 & 333.0 \\
\hline & T4 & 34.7 & 23.4 & 291.7 \\
\hline \multirow[t]{4}{*}{5.12} & $\mathrm{~T} 1$ & 12.1 & 5.4 & 172.9 \\
\hline & T2 & 19.1 & 8.2 & 281.3 \\
\hline & T3 & 26.0 & 13.1 & 333.0 \\
\hline & T4 & 34.7 & 23.4 & 291.7 \\
\hline \multirow[t]{4}{*}{5.18} & $\mathrm{~T} 1$ & 12.1 & 4.9 & 188.4 \\
\hline & T2 & 19.1 & 7.8 & 291.7 \\
\hline & T3 & 26.0 & 12.7 & 343.3 \\
\hline & $\mathrm{T} 4$ & 34.7 & 23.4 & 291.7 \\
\hline \multirow[t]{4}{*}{5.24} & T1 & 12.1 & 4.8 & 188.4 \\
\hline & T2 & 19.1 & 7.7 & 294.2 \\
\hline & T3 & 26.0 & 12.3 & 353.6 \\
\hline & $\mathrm{T} 4$ & 34.7 & 23.4 & 291.7 \\
\hline \multirow[t]{4}{*}{6.5} & $\mathrm{~T} 1$ & 12.1 & 4.6 & 193.6 \\
\hline & T2 & 19.1 & 7.4 & 302.0 \\
\hline & T3 & 26.0 & 12.2 & 356.2 \\
\hline & T4 & 34.7 & 23.4 & 291.7 \\
\hline 0.11 & $\mathrm{~T} 1$ & 12.1 & 4.7 & 191.0 \\
\hline & T2 & 19.1 & 7.3 & 304.6 \\
\hline & T3 & 26.0 & 12.3 & 353.6 \\
\hline & T4 & 34.7 & 23.4 & 291.7 \\
\hline 6.25 & T1 & 12.1 & 5.3 & 175.5 \\
\hline & $\mathrm{T} 2$ & 19.1 & 8.4 & 276.2 \\
\hline & T3 & 26.0 & 13.6 & 320.1 \\
\hline & T4 & 34.7 & 23.4 & 291.7 \\
\hline 7.11 & T1 & 12.1 & 5.0 & 183.3 \\
\hline & $\mathrm{T} 2$ & 19.1 & 8.1 & 283.9 \\
\hline & T3 & 26.0 & 13.3 & 327.8 \\
\hline & T4 & 34.7 & 23.4 & 291.7 \\
\hline 8.12 & $\mathrm{~T} 1$ & 12.1 & 23.1 & 0 \\
\hline & $\mathrm{T} 2$ & 19.1 & 23.1 & 0 \\
\hline & T3 & 26.0 & 23.3 & 69.7 \\
\hline & T4 & 34.7 & 23.4 & 291.7 \\
\hline 9.4 & $\mathrm{~T} 1$ & 12.1 & 17.2 & 0 \\
\hline & $\mathrm{T} 2$ & 19.1 & 20.4 & 0 \\
\hline & T3 & 26.0 & 22.6 & 87.8 \\
\hline & T4 & 34.7 & 23.4 & 291.7 \\
\hline 9.24 & T1 & 12.1 & 8.9 & 82.6 \\
\hline & $\mathrm{T} 2$ & 19.1 & 11.4 & 198.7 \\
\hline & T3 & 26.0 & 15.1 & 281.3 \\
\hline & T4 & 34.7 & 23.4 & 291.7 \\
\hline 10.3 & $\mathrm{~T} 1$ & 12.1 & 7.2 & 126.5 \\
\hline & T2 & 19.1 & 9.1 & 258.1 \\
\hline & T3 & 26.0 & 13.7 & 317.5 \\
\hline & T4 & 34.7 & 23.4 & 291.7 \\
\hline 10.17 & $\mathrm{~T} 1$ & 12.1 & 7.0 & 131.6 \\
\hline & T2 & 19.1 & 8.9 & 263.3 \\
\hline & T3 & 26.0 & 13.4 & 325.2 \\
\hline & $\mathrm{T} 4$ & 34.7 & 23.4 & 291.7 \\
\hline
\end{tabular}

$\overline{\mathrm{SWC}_{2}}$, the proportion of soil moisture that accounts for field capacity; $\mathrm{SWC}_{1}$, the soil moisture before irrigation. between $\mathrm{T} 3$ and $\mathrm{T} 4$, there was no significant difference in the RSA between T2 and T4. Although there were no significant differences among $\mathrm{T} 2, \mathrm{~T} 3$, and $\mathrm{T} 4$, the RV values in $\mathrm{T} 2, \mathrm{~T} 3$, and $\mathrm{T} 4$ were $1.9,2.3$, and 2.4 times greater than that in T1 $(P<0.01)$, respectively. However, the RMD of both varieties decreased with increasing irrigation amount. In 'Arbosana', the RMD in T1 was significantly different from that in T4 $(P<0.05)$, whereas the RMD in 'Arbequina' showed no significant differences among irrigation amounts.

Vertical distribution of olive root responses to irrigation in one dimension. In the $\mathrm{VD}$, the RLD and RSA of the different treatments responded to irrigation by obeying an obvious and similar rule (Figs. 4 and 5). At the same irrigation level, both the RLD and RSA showed a tendency to decrease with increasing soil depth. The RLD and RSA values at the 0 - to $20-\mathrm{cm}$ depth were $1.3-2.6$ times greater than those at the 20- to $40-\mathrm{cm}$ depth and 1.64.0 times greater than those at the $40-$ to $60-\mathrm{cm}$ depth. In addition, the RLD and RSA in the VD were $12 \%$ to $86 \%$ greater than those in the PD. With the exception that the RLD and RSA showed no significant differences among soil depths in T4 for 'Arbosana', both variables at the 0 - to $20-\mathrm{cm}$ depth were significantly higher than those at the other depths $(P<0.05)$ at each irrigation level for both varieties, but there was no significant difference between the 20- to $40-\mathrm{cm}$ and the $40-$ to $60-\mathrm{cm}$ depths $(P>0.05)$. In addition, there was a significant difference between the VD and PD.

When comparing different irrigation levels at the same depth, irrigation changed the RLD and RSA of the olive roots, but the responses to irrigation differed between the two varieties. In 'Arbosana', the variables increased at first but then decreased with increasing irrigation amount. In 'Arbequina', the RLD and RSA increased monotonically with the increasing irrigation amount, reaching a maximum value in T4. In both varieties, the two variables in T2, T3, and T4 were significantly higher than those in $\mathrm{T} 1$. These results also indicated that the irrigation was not responsible for the significant differences of root variables among the three soil depths. However, water had a greater influence at the 20 - to $40-\mathrm{cm}$ and $40-$ to $60-\mathrm{cm}$ depths than at the $0-$ to $20-\mathrm{cm}$ depth, and there was a larger influence on the variables in the VD than those in the PD. For example, in 'Arbequina', compared with the variable at the three soil depths in T1, the RLD in T2, T3, and T4 increased by $150 \%, 168 \%$, and $197 \%$ in the PD, respectively, whereas it increased by $199 \%, 292 \%$, and $233 \%$ in the VD, respectively.

Horizontal distribution of olive root responses to irrigation in one dimension. The RLD and RSA showed similar regulation in the horizontal direction among the different treatments (Figs. 6 and 7). The horizontal distribution of roots was significantly related to the radial distance. The RLD and RSA decreased with increasing radial distance. The roots were mostly distributed within 


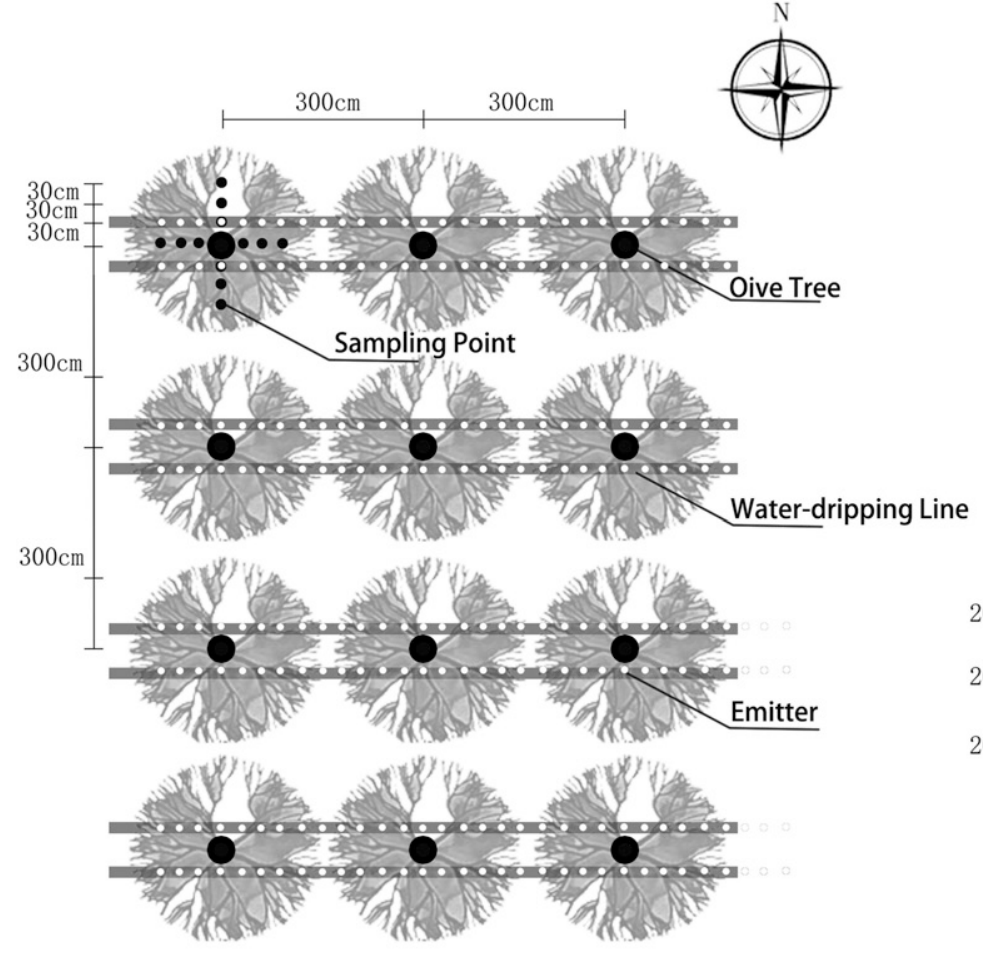

A

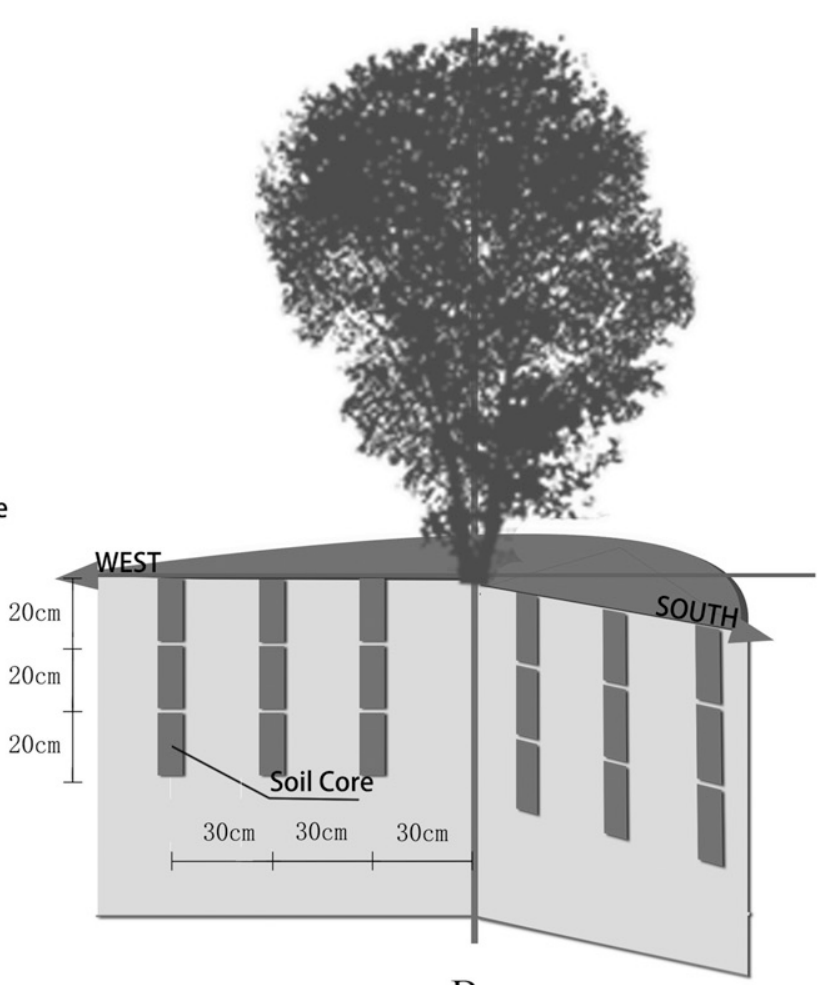

B

Fig. 2. Layout of root sampling. (A) Top view of study site and root sampling. (B) Root sampling profile.
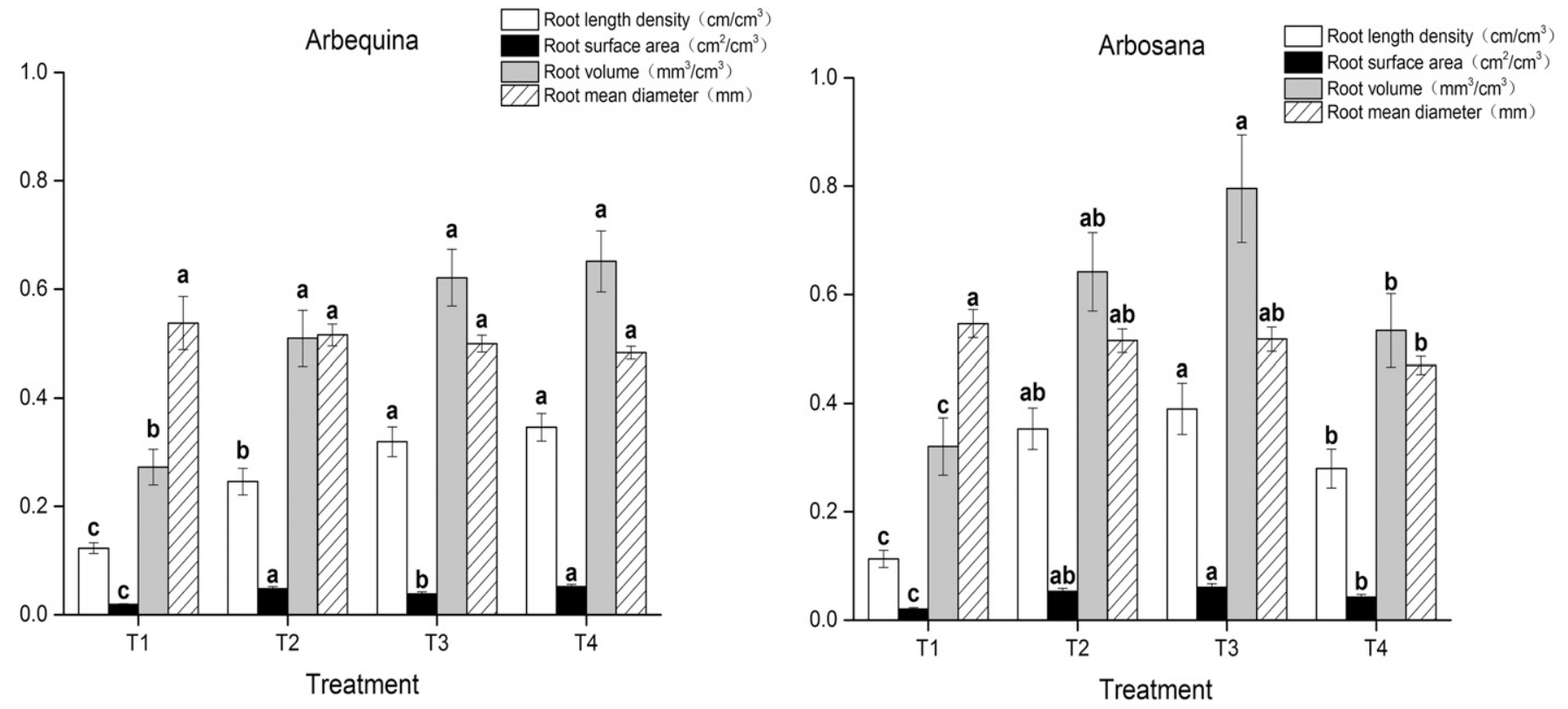

Fig. 3. The effect of root length density, root surface area, root volume, and root mean diameter under different irrigation treatments. Different letters in different treatments indicate significant differences $(P=0.05)$ according to the Duncan test.

a radial distance of $30 \mathrm{~cm}$. In this area, the RLD ranged from 0.133 to $0.623 \mathrm{~cm} \cdot \mathrm{cm}^{-3}$, accounting for $40 \%$ to $78 \%$ of the total in each direction, whereas at radial distances of 60 and $90 \mathrm{~cm}$, the RLD values accounted for $15 \%$ to $38 \%$ and $7 \%$ to $28 \%$, respectively. The RSA of the $30-\mathrm{cm}$ radial region ranged from 0.024 to $0.104 \mathrm{~cm}^{2} \cdot \mathrm{cm}^{-3}$, accounting for $42 \%$ to $75 \%$ of the total in each direction. In addition, the $60-\mathrm{cm}$ radial region accounted for $18 \%$ to $37 \%$, whereas the $90-\mathrm{cm}$ radial region accounted for $6 \%$ to $26 \%$. The values of RLD and RSA in the VD were greater than those in the PD at each radial distance, with the exception of $30 \mathrm{~cm}$. For example, in T3 of Arbosana, the RLD accounted for $55 \%$ in the $\mathrm{PD}$ and $40 \%$ in the VD. In addition, the difference between the $30-$ and $60-\mathrm{cm}$ and
60- and $90-\mathrm{cm}$ radial areas in the PD was larger than that in the VD.

The contrast analysis showed that between different water conditions at the same radial distance, irrigation changed the RLD and RSA at the same radial distance, but in 'Arbosana', the RLD reaching a maximum in T3. In 'Arbequina', however, the RLD increased with the irrigation amount, reaching 

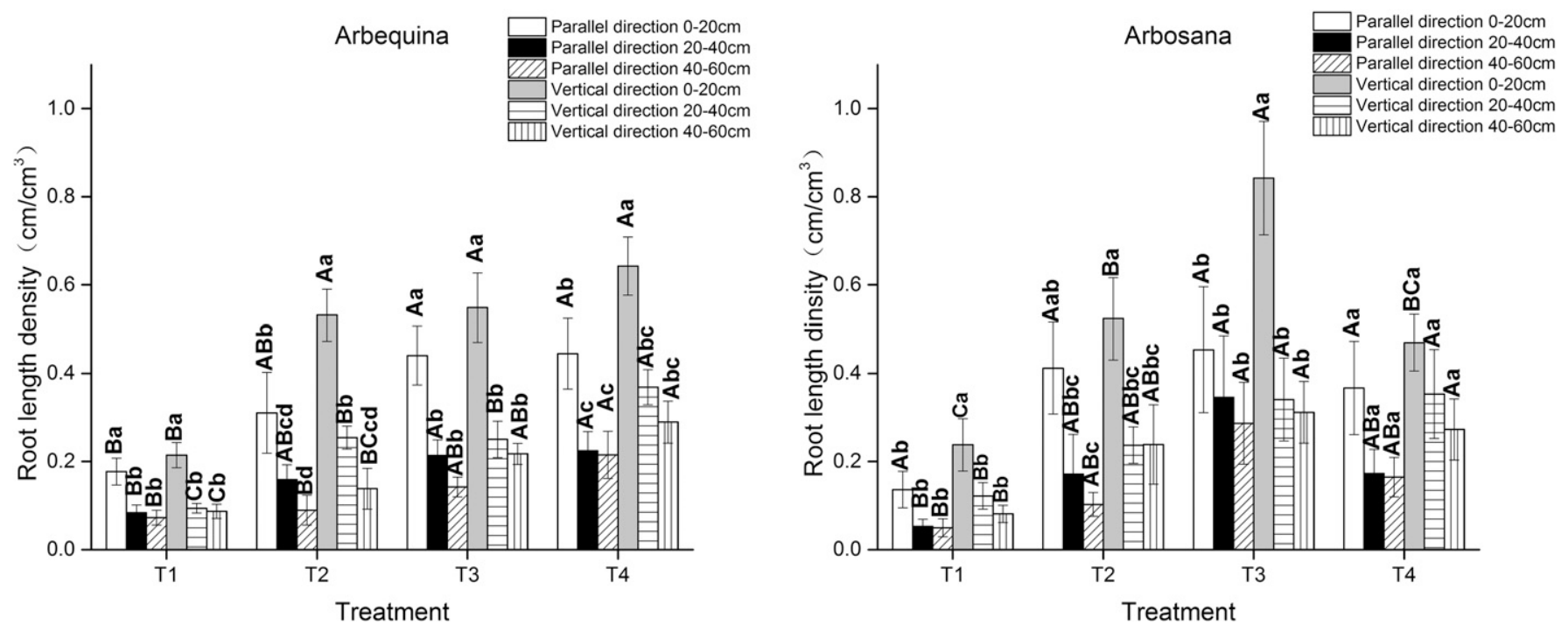

Fig. 4. The vertical distribution of root length density under different irrigation treatments. Different small letters in different treatments indicate significant differences in different soil layers of same process; different capital letters indicate significant differences among different treatments of the same soil layer $(P=0.05)$ according to the Duncan test.
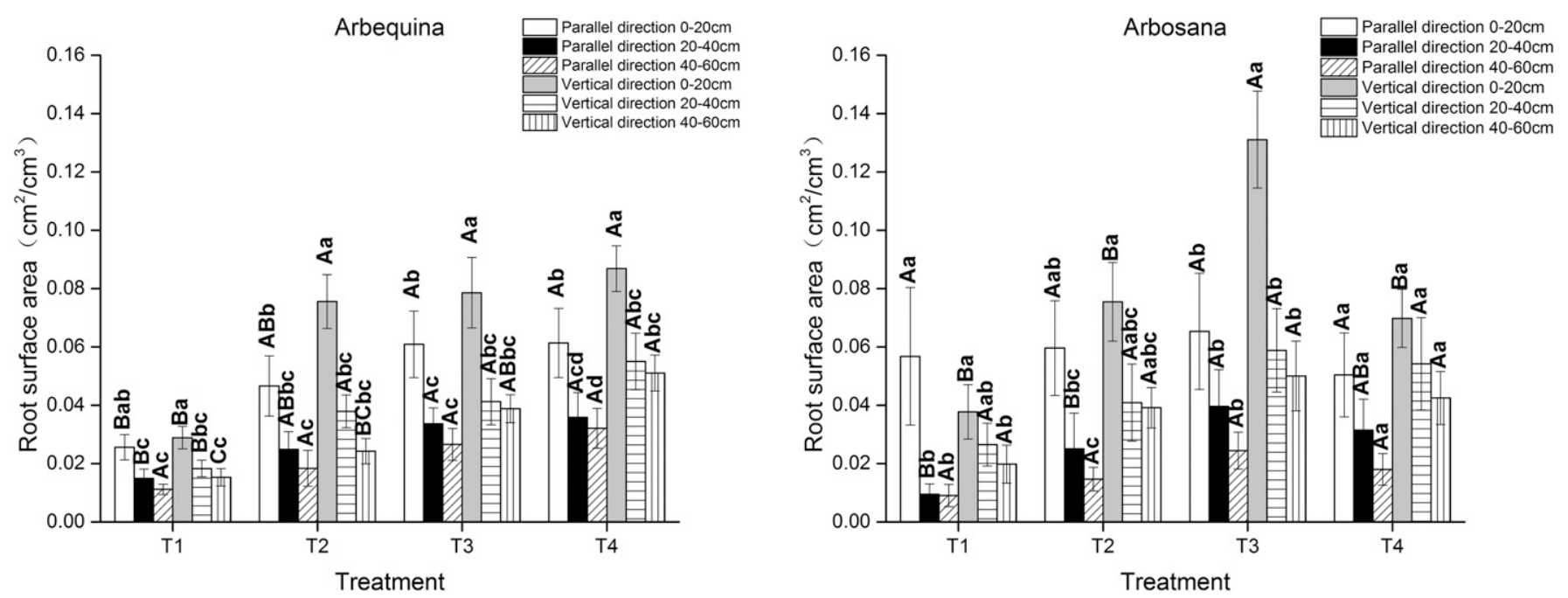

Fig. 5. The vertical distribution of the root surface area under different irrigation treatments. Different small letters in different treatments indicate significant differences in different soil layers of same process; different capital letters indicate significant differences among different treatments of the same soil layer $(P=0.05)$ according to the Duncan test.

a maximum in T4. The RLD and RSA in T1 were significantly lower than those in $\mathrm{T} 2, \mathrm{~T} 3$, and T4 $(P<0.05)$, but the differences among $\mathrm{T} 2$, T3, and T4 were not significant. With increasing irrigation amounts, the RLD and RSA in the $30-\mathrm{cm}$ radial area accounted for a larger proportion, and the variables in the VD changed less than those in the PD. Such as the RLD in 'Arbequina', T1 and T4 accounted for $44 \%$ and $59 \%$ of the total in the $\mathrm{PD}$, respectively, and $40 \%$ and $42 \%$ in the $\mathrm{VD}$, respectively.

Two-dimensional distribution of olive root responses to irrigation. Figure 8 shows the two-dimensional distribution of the RLD and RSA under different irrigation treatments (at a depth of 0-60 cm and radial distance of 0-90 cm) in 'Arbosana' and 'Arbequina'. Irrigation did not change the two-dimensional distribution of the two indexes. In addition to the values of RLD and RSA having a similar tendency, a rather large spatial variation occurred in which the roots gradually increased and assembled toward the soil surface, mainly concentrating within a radial distance of $60 \mathrm{~cm}$ and a depth of $20 \mathrm{~cm}$. In addition, the values of RLD and RSA were higher in the VD than in the PD. For example, in T3 of 'Arbosana', the total RLD value in the VD was $4.941 \mathrm{~cm} \cdot \mathrm{cm}^{-3}$, which was 1.4 times greater than that in the PD $\left(3.485 \mathrm{~cm} \cdot \mathrm{cm}^{-3}\right)$.

Figure 8 more directly shows how irrigation affects the RLD and RSA of olive trees and how different varieties respond to the irrigation amount. It also indicates that roots are distributed more intensively with increasing irrigation amounts, causing most roots to spread in the soil surface around the trunk. For example, in T3 of 'Arbosana', the total RLD and RSA values within the radial distance of $0-60 \mathrm{~cm}$ and at a depth of $0-20 \mathrm{~cm}$ accounted for $41 \%$ and $42 \%$ of the total, respectively, whereas in $\mathrm{T} 1$, they only accounted for $35 \%$ and $38 \%$, respectively.

\section{Discussion}

Root distribution response to irrigation amount. Under different irrigation amounts, the RLD and RSA values decreased within a soil depth of $60 \mathrm{~cm}$. The irrigation over the ground did not change the vertical distribution pattern of olive roots within the $60-\mathrm{cm}$ soil depth. This agrees with previous findings in olive and other trees (Fernández et al., 1991; Zhang et al., 2013). This phenomenon may occur because under the four irrigation amounts, the availability of soil resources gradually decreases with increasing soil depth because the differences in availability 

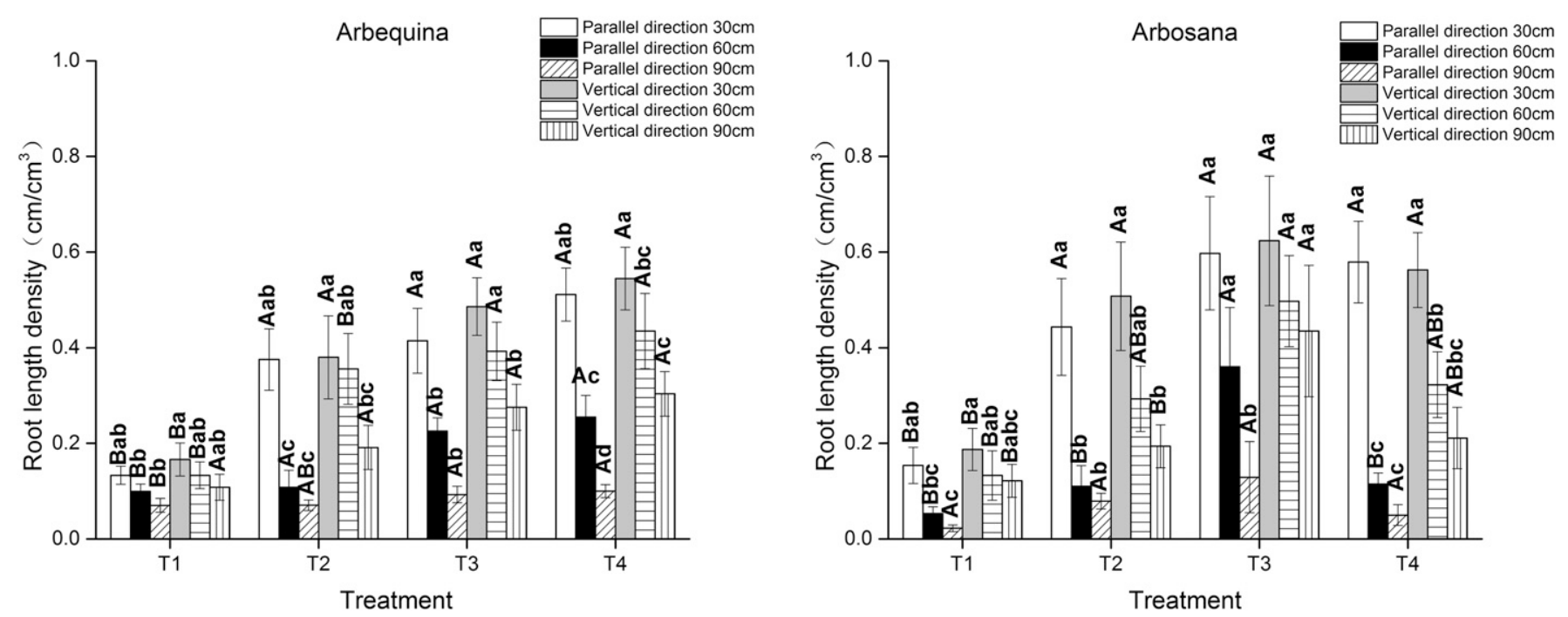

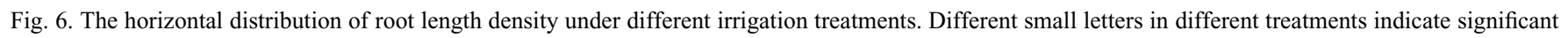
differences at different radial distances of same process; different capital letters indicate significant differences among different treatments of the same radial distance $(P=0.05)$ according to the Duncan test.
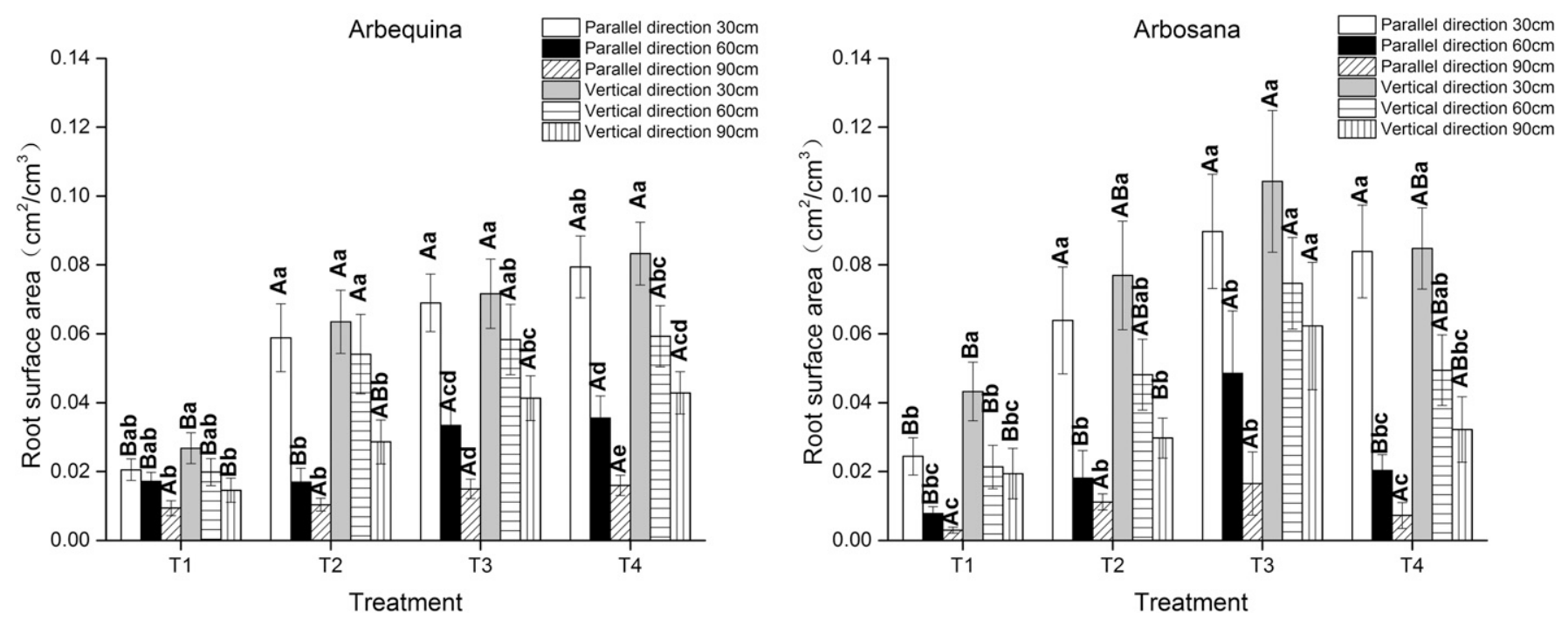

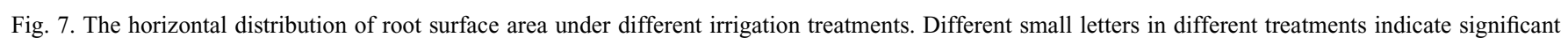
differences at different radial distances of same process; different capital letters indicate significant differences among different treatments of the same radial distance $(P=0.05)$ according to the Duncan test.

in the soil among different soil depths leads to differences of RLD in the vertical distribution (Mei et al., 2006), and RSA is positively correlated with RLD (Zhu et al., 2009). Therefore, we can conclude that surface drip irrigation did not change the different availability of soil resources in the vertical distribution. In addition, irrigation was not the main limiting factor affecting the vertical distribution of olive roots. It has been indirectly demonstrated that the vertical root distribution is mainly influenced by the combination of the hereditary characters and the availability of soil resources (Chen et al., 2005).

In the different irrigation treatments, the olive roots were mainly distributed in the surface soil layer $(0-20 \mathrm{~cm})$, and their proportion reached $40 \%$ to $78 \%$ of the total. Both
Fernández et al. (1991) and Searles et al. (2009) reported the same conclusion. The possible reasons for olive root distribution in the surface soil layer are as follows: First, olive hereditary characteristics influence root distribution. During evolution, olive trees were constantly adapting to the climate of the area of origin (the Mediterranean), and the species could have formed special hereditary characteristics in which the roots tend to be distributed toward the soil surface to better absorb and use surface water and rainwater (Fernández and Moreno, 1999). Second, the surface soil layer contains more nutrition because dry branches and fallen leaves have been decomposed by soil microorganisms and protozoa (An et al., 2007), adding to the suitable soil bulk density and texture (Burke et al., 1991), moisture, and temperature
(Pregitzer et al., 1995). Third, the drip irrigation system plays a role. Many studies have indicated that drip irrigation can cause roots to be distributed in the surface layer because the surface soil is moist and roots have a positive water tropism (Zhao et al., 2012).

The RLD, which is significantly influenced by radial distance, decreased with increasing radial distance, as did the RSA. This phenomenon has also been observed in E. angustifolia (Zhao et al., 2012) and Juglans regia (Wang et al., 2013). These root characteristics may be mainly dependent on the hereditary properties of its own developmental construction (Pregitzer et al., 2002). Most olive roots were distributed in the $30-\mathrm{cm}$ radial area, and the proportion of roots there increased with irrigation amount. The possible reasons are as follows. First, the 
Arbequina
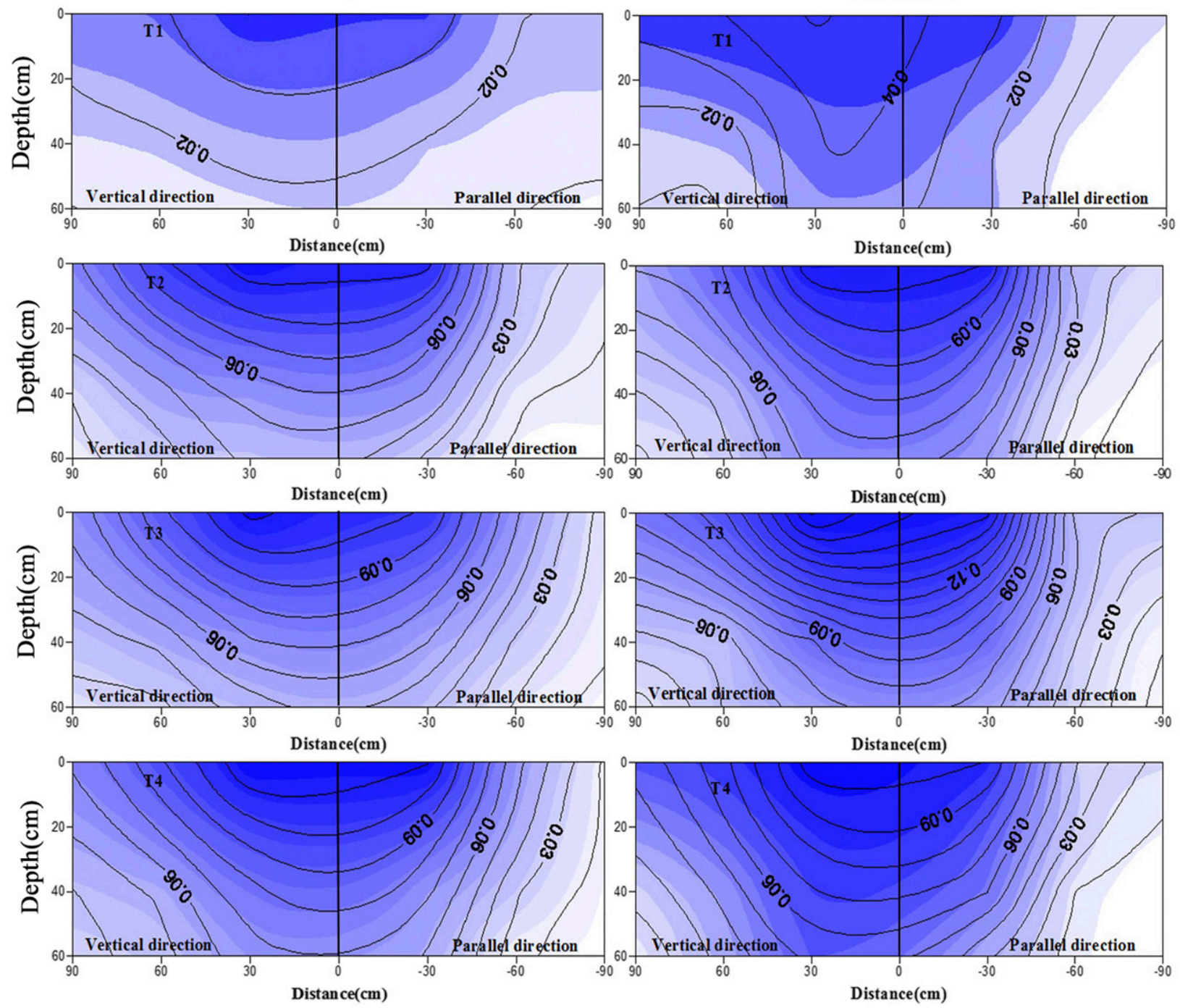

Distance(cm)

Fig. 8. Two-dimensional distribution of root length density (shaded blue to white areas) and root surface area (black isoline, $\mathrm{cm}^{2} \cdot \mathrm{cm}^{-3}$ ) under different irrigation treatments. The solid line in the middle indicates the tree position.

hereditary properties of root development construction play a role (Pregitzer et al., 2002). Second, because the soil around the drip irrigation line was heavily influenced by the drip irrigation and because the irrigation line was arranged at the $30-\mathrm{cm}$ radial distance, the water condition was of high quality there, boosting the availability of water and nutrients in soil, improving the soil structure (Burton et al., 2000; King et al., 2002; Xi et al., 2012) and accelerating root growth.

Root response to irrigation. In different treatments, the morphological variables of olive roots (RLD, RSA, RV, and RMD) responded positively to irrigation. This indicated that a certain amount of irrigation can effectively promote the growth of olive roots. Dichio et al. (2002) also observed that olive root growth responded positively to irrigation, mainly because irrigation vastly improved the availability of soil water (Xi et al., 2012) and perfected the soil structure and the availability of soil resources. The development of the availability of soil resources can promote carbon transfer to the underground parts of trees, therefore promoting the growth of tree roots and development of the roots in absorbing water and nutrients (Burton et al., 2000; King et al., 2002). In addition, roots tend to grow toward water. Thus, increasing the irrigation amount promotes root growth.

In the $\mathrm{VD}$, the irrigation amount had a stronger effect on the $20-$ to $40-\mathrm{cm}$ and 40 - to $60-\mathrm{cm}$ layers than on the $0-$ to $20-\mathrm{cm}$ soil layer, possibly because more irrigation led to more usable water in the deeper soil. Irrigation improved the availability of soil resources (Burton et al., 2000; King et al., 2002) and accelerated the root growth. In addition, the olive roots were mainly distributed in the soil surface. Thus, the irrigation amount had a greater effect on the deeper layers $(20-40 \mathrm{~cm}$ and $40-60 \mathrm{~cm})$.

In each soil layer, there were higher RLD and RSA values in the VD of the drip irrigation line than in the PD, which may be related to the water difference that soil acquires in the two directions. Because the area in the VD was below the drip line, the soil there could obtain more water than in areas of the PD. Because the tree roots tended to be distributed around water, there were some differences in each root variable between the two directions.

In the horizontal direction, roots of the $30-\mathrm{cm}$ radial area accounted for more proportion in the direction parallel to the drip line than in the VD. In addition, there were more significant root differences among radial distances, and the irrigation amount had a greater effect on the roots in the PD. This result may occur because the area moistened by drip irrigation is a circle that gradually spreads outside the emitter center. Thus, the soil could receive less water in the PD than in the VD, and this difference constantly increased with increasing radial distance. Therefore, roots of the $30-\mathrm{cm}$ radial area accounted for more proportion in the PD than in the $\mathrm{VD}$, and there were more significant root differences among radial distances. With 
the increasing irrigation amount, the area in which water diffused was constantly expanding, and thus, soil in the PD received more water, promoting the growth of roots. Therefore, the irrigation amount had a greater effect in the PD than in the VD.

Variety differences in root response to irrigation. Under different irrigation treatments, the different varieties showed different responses to irrigation amounts in terms of the RLD, RSA, RV, and RMD. In 'Arbosana', each root variable increased but then decreased with irrigation amount, reaching a maximum in T3, whereas in 'Arbequina', these variables increased monotonically. The possible reasons are as follows. Plant roots can respond accordingly to water regimes (Feng et al., 1996; Wei et al., 2006), but this type of adaption ability is limited (Li et al., 2010). When 'Arbosana' is fully irrigated, the ventilation conditions worsen, and the water content of the rhizosphere is saturated. With poor air and water conditions, waterlogging and lack of oxygen may reach the roots. This would cause low root activity and moisture absorption rates, leading to poor root growth. The same conclusion has been reported in tomato root growth responding to irrigation amounts (Lavado et al., 1999; Yang et al., 2016). However, when 'Arbequina' trees are fully irrigated, their roots adapt to the water regime and maintain growth.

This study suggests that irrigation did not change the spatial distribution pattern of olive roots, which were mainly distributed at a radial distance of $0-60 \mathrm{~cm}$ and a depth of 0-20 cm; conversely, irrigation did accelerate root growth. However, different responses to irrigation amounts were observed in the different varieties. 'Arbosana' trees should be irrigated until the water content reaches $75 \%$ of the field capacity, whereas 'Arbequina' trees should be irrigated until the water content reaches $100 \%$. Therefore, surface drip irrigation is appropriate for olive trees, and most water should be provided within the $30-\mathrm{cm}$ radial distance from the trunk, and irrigation depth is not easy to more than $20 \mathrm{~cm}$. In addition, different irrigation management regimes should be employed for different varieties.

\section{Literature Cited}

An, H., L.Y. Wei, Y. Liu, and Z.P. Shangguan. 2007. Distribution characters of fine root of artificial Pinus tabulaeformis and natural Betula platyphylla forests and their relation to soil nutrients in Hilly Loess Regions. Plant Nutr. Fert. Sci. 13:611-619.

Fernandes-Silva, A.A., T.C. Ferreira, C.M. Correia, A.C. Malheiro, and F.J. Villalobos. 2010. Influence of different irrigation regimes on crop yield and water use efficiency of olive. Plant Soil 333(1-2):35-47.

Fernandes-Silva, A.A., J.B. Gouveia, P. Vasconcelos, T.C. Ferreira, and F.J. Villalobos. 2013. Effect of different irrigation regimes on the quality attributes of monovarietal virgin olive oil from cv. 'Cobrançosa'. Grasas Aceites 64(1):41-49.

Fernandes-Silva, A.A., Á. López-Bernal, T.C. Ferreira, and F.J. Villalobos. 2016. Leaf water relations and gas exchange response to water deficit of olive (cv. Cobrançosa) in field grown conditions in Portugal. Plant Soil 402:191-209.

Burton, A.J., K.S. Pregitzer, and R.L. Hendrick. 2000. Relationships between fine root dynamics and nitrogen availability in Michigan northern hardwood forest. Oecologia 125:389-399.

Burke, M.K., D.J. Raynal, and M.J. Mrrchell. 1991. Soil nitrogen availability influences seasonal carbon allocation patterns in sugar maple (Acer saccharum). Can. J. For. Res. 22:447-456.

Breton, C., F. Medail, and C. Pinatel. 2006. From olive tree to oleaster: Origin and domestication of Olea europaea L. in the Mediterranean basin. Cah. Agr. 15:329-336.

Cheng, Y.H., Y.Z. Han, Q.C. Wang, and Z.Q. Wang. 2005. Seasonal dynamics of fine root biomass, root length density, specific root length and soil resource availability in a Larix gmelini plantation. Acta Phytoecol. Sin. 29: 403-410.

Connor, D.J. 2005. Adaptation of olive (Olea europea L.) to waterlimited environment. Austral. J. Agr. Res. 56:1181-1189.

d'Andria, R., A. Lavini, G. Morelli, M. Patumi, S Terenziani, D. Calandrelli, and F. Fragnito. 2004. Effects of water regimes on five pickling and double aptitude olive cultivars (Olea europea L.). J. Hort. Sci. Biotechnol. 79:18-25.

Dag, A., A. Ben-Gal, U. Yermiyahu, L. Basheer, N Yogev, and Z. Kerem. 2008. The effect of irrigation level and harvest mechanization on virgin olive oil quality in a traditional rain-fed "Souri" olive orchard converted to irrigation. J. Sci. Food Agr. 88:1524-1528.

Dichio, B., M. Romano, V. Nuzzo, and C. Xiloyannis. 2002. Soil water availability and relationship between canopy and roots in young olive trees (cv. Coratina). Acta Hort. 586:255-258.

Bacelar, E.A., D.L. Santos, J.M. Moutinho-Pereira, J.I. Lopes, B.C. Gonçalves, T.C. Ferreira, and C.M. Correia. 2007. Physiological behaviour, oxidative damage and antioxidative protection of olive trees grown under different irrigation regimes. Plant Soil 292:1-12.

Fernández, J.E., F. Moreno, F. Cabrera, J.L. Arrue, and J. Martín-Aranda. 1991. Drip irrigation, soil characteristics and the root distribution and root activity of olive trees. Plant Soil 133: 239-251.

Fernández, J.E. and F. Moreno. 1999. Water use by the olive tree. J. Crop Prod. 2:101-162.

Feng, G.L., C.M. Liu, and L. Wang. 1996. Roles of soil water in regulating root growth and distribution. Eco-Agric. Res. 4:5-9.

Grattan, S.R., M.J. Berenguer, J.H. Connell, V.S. Polito, and P.M. Vossen. 2006. Olive oil production as influenced by different quantities of applied water. Agr. Water Mgt. 85:133-140.

Gucci, R., E. Lodolni, and H.F. Rapoport. 2007. Productivity of olive trees with different water status and crop load. J. Hort. Sci. Biotechnol. $82: 648-656$.

Gómez del Campo, M. 2007. Effect of water supply on leaf area development, stomatal activity, transpiration, and dry matter production and distribution in young olive trees. Austral. J. Agr. Res. 58:385-391.

Gordon, W.S. and R.B. Jackson. 2000. Nutrient concentrations in fine roots. Ecology 81:275-280.

Jiang, C.Y., D.C. Qi, J. Su, and Y.P. Zhao. 2006. Status and developing countermeasures of olive production in Gansu province. Nonwood Forest Res. 12:11-17.

King, J.S., T.J. Albaugh, and H.L. Allen. 2002. Below-ground carbon input to soil is controlled by nutrient availability and fine root dynamics in loblolly pine. New Phytol. 154:389-398.
Lavado, M.M., M.J. Moñino, and M.I. García. 1999. Root water absorption pattern in a processing tomato crop under different irrigation strategies. Third International Symposium. Irrigation of Horticultural Crops 537:839-845.

Lavee, S., E. Hanoch, M. Wodner, and H. Abramowitch. 2007. The effect of predetermined water deficit on the performance of $\mathrm{cv}$. Muhasan olives (Olea europea $\mathrm{L}$.) in the eastern coastal plain of Israel. Sci. Hort. 112:156-163.

Levin, I., R. Assaf, and B. Bravdo. 1979. Soil moisture and root distribution in an apple orchard irrigated by tricklers. Plant Soil 52:31-40.

Li, W.Y., S.Q. Zhang, S.Y. Ding, and C. Shan 2010. Root morphological variation and water use in alfalfa under drought stress. Acta Ecol. Sin. 30:5140-5150.

Ma, L.H., P.T. Wu, and Y.K. Wang. 2012. Spatial distribution of roots in a dense jujube plantation in the semiarid hilly region of the Chinese Loess Plateau. Plant Soil 36:292-301.

Mei, L., Z.Q. Wang, Y.Z. Han, J.C. Gu, X.R. Wang, Y.H. Cheng, and X.J. Zhang. 2006. Distribution patterns of Fraxinus mandshurica root biomass specific root length and root length density. Chin. J. Appl. Ecol. 17:1-4.

Moriana, A., F.J. Villalobos, and E. Fereres. 2002. Stomatal and photosynthetic responses of olive (Olea europea L.) leaves to water deficit. Plant Cell Environ. 25:395-405.

Moriana, A., F. Orgaz, M. Pastor, and E. Fereres. 2003. Yield responses of a mature olive orchard to water deficit. J. Amer. Soc. Hort. Sci. 128:425-431.

Ning, D.L., B. Lu, C.H. Du, Y.J. Li, Y.J. Liao, Y.L. Zhang, and H.Y. Chen. 2010. Development situation, problems and countermeasures of olive industry in Yunnan province. Nonwood Forest Res. 28:146-149.

Pregitzer, K.S., D.R. Zak, and P.S. Curtis. 1995 Atmospheric $\mathrm{CO}_{2}$, soil nitrogen and turnover of fine roots. New Phytol. 129:579-585.

Pregitzer, K.S., J.L. Deforest, and A.J. Burton. 2002. Fine root architecture of nine North American trees. Ecol. Monogr. 72:293-309.

Ramos, A.F. and F.L. Santos. 2010. Yield and olive oil characteristics of a low-density orchard (cv. Cordovil) subjected to different irrigation regimes. Agr. Water Mgt. 97:363-373.

Schenk, H.J. and R.B. Jackson. 2002. Rooting depths, lateral root spreads and below-ground/ above-ground allometries of plants in waterlimited ecosystems. J. Ecol. 90:480-494.

Searles, P.S., D.A. Saravia, and M.C. Rousseaux. 2009. Root length density and soil water distribution in drip-irrigated olive orchards in Argentina under arid conditions. Crop Pasture Sci. 60:280-288.

Tang, W.B., H.B. Deng, Y.H. Xiao, G.L. Zhang, K. Fan, H. Mo, and L.Y. Chen. 2010. Root characteristics of high-yield C Liangyou rice combinations of two-line hybrid rice. Scientia Agricultura Sinica 43:2859-2868.

Vossen, P. 2007. Olive oil: History, production and characteristics of the world's classic oils. HortScience 42:1093-1110.

Wang, L., Y.J. Ma, J.H. Zhao, and M. Hong. 2013 Study on characteristic of root distribution of walnut tree under condition of drip irrigation in arid area. J. Water Res. Water Eng. 24:9295.

Wei, S., S.M. Ren, P.L. Yang, and M.J. Yan. 2006. Soil moisture dynamic and root growth of alfalfa in Wei Chang region. Chinese Agricultural Science Bulletin 22:448-451.

Xi, B.Y., Y. Wang, L.M. Jia, J. Si, and D.K. Xiang. 2011. Property of root distribution of triploid Populus tomentosa and its relation to root water 
uptake under the wide-and-narrow row spacing scheme. Acta Ecol. Sin. 31:47-57.

Xi, B.Y., Y. Wang, N. Di, L.M. Jia, G.D. Li, X.F. Huang, and Y.Y. Gao. 2012. Effects of soil water potential on the growth and physiological characteristics of Populus tomentosa pulpwood plantation under subsurface drip irrigation. Acta Ecol. Sin. 32:5318-5329.

Yang, Z.Q., Y.X. Qiu, Z.X. Liu, Y.Q. Chen, and W. Tan. 2016. The effects of soil moisture stress on the growth of root and above-ground parts of greenhouse tomato crops. Acta Ecol. Sin. 36:46-52.

Yan, X.L., T.F. Dai, C.S. Xing, L.M. Jia, and L.N. Zhang. 2015. Coupling effect of water and nitrogen on the morphology and distribution of fine root in surface soil layer of young Populus Xeuramericana plantation. Acta Ecol. Sin. 35(11):3692-3701.

Zhang, L.N., D.K. Xiang, B.Y. Xi, and L.M. Jia. 2013. Response of the fine roots of triploid Populos tomentosa to different subsurface drip irrigation treatments in shallow soil layers. J. Northeast For. Univ. 43:40-44.

Zhao, X.F., H.L. Xu, X.H. Liu, P. Zhang, Z.Y. Liu, and H. Hong. 2012. Angustifolia shelterbelt root distribution characteristics of extreme drought area under different irrigation. Prog. Geogr. 31:646-653.

Zhu, M.Q., C.M. Ma, M.P. Zhai, and X.Y. Wang. 2009. Fine roots distribution characteristics of Zanthoxylum bungeanum in the rocky mountainous area of Hebei. Scientia Silvae Sinicae 45:131-135. 